\title{
X-ray computed tomography study of kink bands in unidirectional composites
}

DOI:

10.1016/j.compstruct.2016.10.124

\section{Document Version}

Accepted author manuscript

Link to publication record in Manchester Research Explorer

\section{Citation for published version (APA):}

Wang, Y., Burnett, T., Chai, Y., Soutis, C., Hogg, P., \& Withers, P. (2017). X-ray computed tomography study of kink bands in unidirectional composites. Composite Structures, 160, 917-924.

https://doi.org/10.1016/j.compstruct.2016.10.124

\section{Published in:}

Composite Structures

\section{Citing this paper}

Please note that where the full-text provided on Manchester Research Explorer is the Author Accepted Manuscript or Proof version this may differ from the final Published version. If citing, it is advised that you check and use the publisher's definitive version.

\section{General rights}

Copyright and moral rights for the publications made accessible in the Research Explorer are retained by the authors and/or other copyright owners and it is a condition of accessing publications that users recognise and abide by the legal requirements associated with these rights.

\section{Takedown policy}

If you believe that this document breaches copyright please refer to the University of Manchester's Takedown Procedures [http://man.ac.uk/04Y6Bo] or contact uml.scholarlycommunications@manchester.ac.uk providing relevant details, so we can investigate your claim.

\section{OPEN ACCESS}




\section{Accepted Manuscript}

X-ray Computed Tomography Study of Kink Bands in Unidirectional Composites

Ying Wang, Timothy L. Burnett, Yuan Chai, Costas Soutis, Paul J. Hogg, Philip

J. Withers

PII:

S0263-8223(16)31715-9

DOI: http://dx.doi.org/10.1016/j.compstruct.2016.10.124

Reference: COST 7950

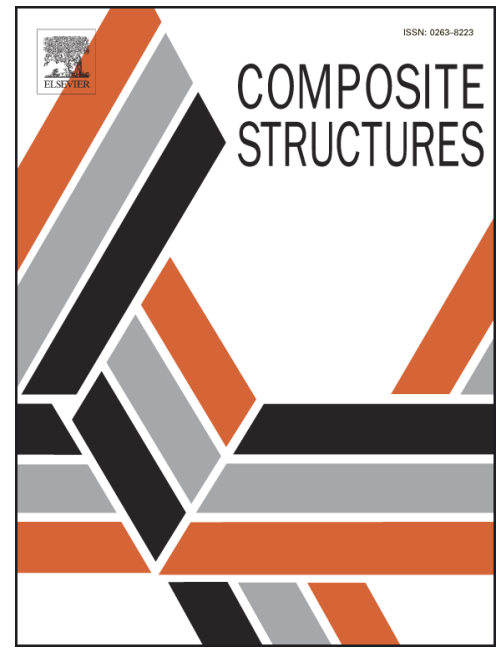

Received Date: 7 September 2016

Accepted Date: $\quad 29$ October 2016

Please cite this article as: X-ray Computed Tomography Study of Kink Bands in Unidirectional Composites, Composite Structures (2016), doi: http://dx.doi.org/10.1016/j.compstruct.2016.10.124

This is a PDF file of an unedited manuscript that has been accepted for publication. As a service to our customers we are providing this early version of the manuscript. The manuscript will undergo copyediting, typesetting, and review of the resulting proof before it is published in its final form. Please note that during the production process errors may be discovered which could affect the content, and all legal disclaimers that apply to the journal pertain. 


\title{
X-ray Computed Tomography Study of Kink Bands in Unidirectional
}

\section{Composites}

\section{Ying Wang ${ }^{1}$, Timothy L. Burnett ${ }^{1}$, Yuan Chai ${ }^{2}$, Costas Soutis ${ }^{2}$, Paul J. Hogg ${ }^{3}$ and Philip}

\section{J. Withers ${ }^{1 *}$}

${ }^{1}$ Henry Moseley X-ray Imaging Facility, School of Materials, University of Manchester, M13 9PL, UK

${ }^{2}$ School of Materials, University of Manchester, M13 9PL, UK

${ }^{3}$ Royal Holloway, University of London, TW20 0EX, UK

*Corresponding author: p.j.withers@manchester.ac.uk

\begin{abstract}
An experimental study on the axial compressive failure of cylindrical unidirectional (UD) carbon fibre-epoxy rods has been performed to better understand kink bands and the relevant damage mechanisms in three dimensions (3D). Post-mortem X-ray micro-computed tomography (micro-CT) imaging has shown that fibre kink bands predominantly all lie within the same plane in a cylindrical rod sample uniaxially compressed without lateral constraint. Kink bands at different stages of development are contained in the damage volume and the geometric parameters of fully developed kink bands are consistent through the damage zone, with a kink-band width $\omega \approx 20-320 \mu \mathrm{m}$, kink-band angle $\beta \approx 11-40^{\circ}$ and fibre rotation angle $\Phi\left(\varphi+\varphi_{o}\right) \approx 18-52^{\circ}$. Fibre failure, longitudinal splitting and matrix micro-cracks within the fibre kink zone are identified by scanning electron microscopy (SEM) and X-ray micro-CT observations. The smallest radius of curvature that corresponds to maximum amount of bending of the unbroken buckled fibres was $\sim 280 \mu \mathrm{m}$ (40 fibre diameters). Kink-band
\end{abstract}


boundary planes and longitudinal splitting have been extracted and visualised in 3D for the first time.

Keywords: Resin infusion; Carbon fibre reinforced plastic (CFRP); Fibre micro-buckling; Fibre kinking; Longitudinal splitting; X-ray computed tomography (CT)

\section{Introduction}

Carbon fibre reinforced plastics (CFRPs) are an important category of fibre reinforced composites widely used in high-performance space, aircraft and automotive structures, due to their high specific strength and specific stiffness, which offer an attractive approach to substantially reduce the weight of these structures. However, one crucial factor limiting the design of structures composed of CFRPs is the susceptibility of the material to compressive load.

Experiments on CFRPs have indicated compressive strengths that are 60-70\% 0f the reported tensile strengths [1-3]. As compressive loads naturally arise in many mechanical structures either deliberately or accidentally, large safety margins are incorporated in current composite designs, resulting in overweight and inefficient structures [4]. Thus, the advantage of high specific strengths of composite materials cannot be fully exploited.

Although the first report on the low compressive strength of fibre composites resulting from fibre micro-buckling (kinking) and kink bands appeared in 1960 [5], this subject is still an active field of research in recent years. In part this is because of the sudden and uncontrolled nature of compressive failure. The tensile properties of unidirectional (UD) fibre composites are generally dominated by the reinforcing fibres whereas, under compression, the matrix and the interface play a more significant role as they provide the lateral support and constraint to fibres. In addition, in contrast to tensile failure, compressive failure can be very sensitive to 
small fibre misalignment and imperfections introduced during manufacturing, because these manufacturing defects can initiate fibre buckling that leads to fibre kinking [6]. Compressive failure of fibre composites takes a variety of forms at the micro-scale, including fibre microbuckling, fibre kinking, fibre compressive failure, fibre shear failure, matrix shear deformation and longitudinal splitting along the interface or in the matrix [7-10]. In an effort to investigate the micromechanics of kink-band formation, both post mortem and in situ characterisation using a combination of optical microscopy and scanning electron microscopy (SEM) has been undertaken [10-15]. Post-failure sectioning planes or surface plane at different loading levels have been carefully studied but can only reveal the geometry and evolution of kink bands lying in the kink plane, but it is likely that the damage mechanisms interact in three dimensions (3D). However, until recently it has not been possible to observe the kink-band morphology in 3D at resolutions sufficient to image the $7 \mu \mathrm{m}$ carbon fibres- -

X-ray micro-computed tomography (micro-CT) can be used to quantify the $3 \mathrm{D}$ microstructure of materials at a spatial resolution on the scale of a few microns [16]. Originally employed in medical imaging to derive non-invasive images of the bones and tissues in human body [17], X-ray micro-CT has now gained popularity as a non-destructive testing (NDT) technique to assess defects and damage in materials and mechanical structures. Furthermore as a non-destructive imaging method it can be used to follow damage events over time (so-called four-dimensional or time-lapse studies). Recently, X-ray micro-CT has been employed to inspect defects and damage in composites such as matrix cracks $[18,19]$, voids [20,21], fibre fractures [22], delamination [23,24] and very recently kink bands [25,26] although at a resolution $(\sim 5 \mu \mathrm{m})$ that was not good enough to resolve individual fibres in the micro-buckling region or to segment and visualise damage in 3D. 
Considering the intrinsic low contrast between carbon fibre and epoxy matrix in X-ray tomograms, one of the main challenges in this project was to design a specimen geometry for kink bands to be observed by X-ray micro-CT. Conventionally, compression tests are carried out on either small rectangular beams or plates cut from unidirectional laminates. From an Xray imaging viewpoint the high aspect ratio would limit penetration of the X-rays, which can lead to artefacts lowering the image quality [27]. In addition, anti-buckling devices to prevent Euler buckling of samples are often employed, which would obstruct the X-ray beam. As discussed by Maire and Withers [16], to obtain $\sim 1 \mu \mathrm{m}$ voxel size on a 2048-pixel detector, the region of interest (RoI) imaged must be smaller than $\sim 2 \mathrm{~mm}$. Consequently we have examined the compression of small-diameter cylindrical composite rods to optimise the image quality for analysis of the micro-scale damage mechanisms. Furthermore, direct end loading is often chosen for testing of un-standardised specimens due to its simplicity [28]. Composite cylinders without end constraint tend to fail by brooming, while the failure mode changes to the formation of kink bands in end-constrained composite cylinders [29]. In view of this, end-constrained composite specimens were employed to ensure the formation of kink bands.

In this study, high-quality small-diameter end-constrained cylindrical UD carbon fibre-epoxy rods have been manufactured and tested to study the compressive failure. SEM and X-ray micro-CT observations have been correlated aiming to comprehensively characterise the post-failure geometry of kink bands in 3D and to identify the damage mechanisms associated with the formation of kink bands. 


\section{Materials and Methods}

\subsection{Composite Test-Piece Manufacture}

As the compressive failure of UD composites is sensitive to manufacturing defects, it is of great importance to ensure the quality of the composite samples by using the appropriate manufacturing method. In order to manufacture high quality (high fibre volume fraction and good fibre alignment) small-diameter cylindrical composite rods, a novel manufacturing method, adapted from the conventional resin infusion process used to manufacture large composite panels, was developed. This small-scale resin infusion (SSRI) method was used here to fabricate UD composite rods, consisting of Torayca T700 carbon fibre (7 $\mu \mathrm{m}$ diameter) yarns and Huntsman Araldite LY 564/XB 3486 epoxy resin.

In the SSRI method, a glass tube was used as a closed mould with the two ends connected to plastic tubes acting as the resin inlet and outlet. Dry fibres were placed into the glass tube (inner diameter $2.4 \mathrm{~mm}$ ) before resin infusion. As the cross-section of the glass tube is predetermined, the fibre volume fraction can be easily tailored by changing the number of fibres. A resin trap made with a plastic bag and cotton breather was attached to the outlet tubing, preventing extra resin from flowing into the vacuum pump. Fig. 1 shows the experimental set-up of the SSRI method.

With a vacuum pump drawing resin through the glass tube, fibres were observed to move towards the resin-outlet direction when wetted-out. In order to minimise fibre misalignment or waviness induced by fibre movement during infusion, a Y- or T-connector (outer diameter $6 \mathrm{~mm}$ ) was added between the glass tube (inner diameter $2.4 \mathrm{~mm}$ and outer diameter $4 \mathrm{~mm}$ ) and the inlet tubing. One end of the connector was connected to the glass tube via a short length of plastic tubing (inner diameter $6 \mathrm{~mm}$ ) while the fibres were passed through the second end and fixed with sealing tape; the third end was connected to the resin inlet tube. 
After infusion, the composite was cured at $80{ }^{\circ} \mathrm{C}$ for eight hours. The sample rod was then demoulded and cut into $20 \mathrm{~mm}$ long specimens for compression testing.

The 2.4 mm-diameter rods contains six tows of carbon fibres with each fibre tow containing 12,000 fibres (carbon fibre diameter $7 \mu \mathrm{m}$ ). Thus, the fibre volume fraction of the composite rods calculated based on the area fraction of fibres in the rod cross-section is $\sim 63 \%$. This value is higher than that of the commonly used pultruded composite rods [30], which will give rise to better performance in fibre-dominated properties of UD composites.

\subsection{Mechanical Testing}

In the uniaxial compression study of CFRP rods by Couque et al. [29], the specimens with a reduced gauge section were inserted in chamfered steel bases to a snug fit for better load transfer. A waisted specimen geometry modified from that used by Couque et al. [30] was employed here, as shown schematically in Fig. 2a. The nominal diameter of the composite rod was $2.4 \mathrm{~mm}$ (equal to inner diameter of the glass tube). The middle section was ground down to a diameter of around $1.5 \mathrm{~mm}$ over a $3 \mathrm{~mm}$ long gauge section, with smooth radii at the transition regions. The two ends of the specimen were then bonded with an epoxy adhesive (Araldite® Strength in Bonding 2000+) into chamfered aluminium end caps having small holes drilled to remove any surplus epoxy. Axial compressive end loading was applied to the specimens via the platens of an Instron 5569 machine under a constant displacement rate of $0.02 \mathrm{~mm} / \mathrm{min}$ and ten samples were tested in total.

\subsection{Damage Characterisation}

The composite rods were CT scanned on a Zeiss Xradia 520 Versa X-ray microscope in the Henry Moseley X-ray Imaging Facility (HMXIF) at the University of Manchester before machining and sample preparation to assess the material quality. Specimens that had 
completely failed into two halves were prepared for SEM examination of the fracture surfaces to observe the $2 \mathrm{D}$ damage pattern. X-ray micro-CT imaging was performed to study the 3D damage morphology. A partly failed specimen was scanned on a Zeiss Xradia $400 \mathrm{X}$ ray microscope at HMXIF. The parameters of the X-ray micro-CT scans are listed in Table 1.These imaging conditions essentially exhibit absorption contrast. The Feldkamp-DavisKress (FDK) algorithm [31] was used for reconstruction and the reconstructed volume was imported to Avizo 8.0 software (FEI Visualisation Sciences Group) for 3D data analysis. Cracks were segmented on the basis of greyscale (attenuation) differences using an automatic local region-growing segmentation tool and modified with the manual brush tool within a limited intensity range. Interpolation was used on every ten cross-sections and the 3D segmentation was confirmed by comparing to the raw data 2D virtual cross-sections.

\section{Results and Discussion}

\subsection{Characterisation of manufactured composite sample}

The onset of compression failure is controlled by the initial fibre architecture and sample quality. The as-manufactured condition has been evaluated by a combination of optical microscopy of 2D sections and 3D analysis of X-ray tomograms. Some degree of fibre misalignment is inevitable in the manufacturing of long fibre reinforced composite materials, especially during the manual handling of fibres. Fig. 3a shows a typical X-ray micro-CT virtual cross-section taken so as to include the nominal fibre axis of the composite rod. Fibre waviness and misalignment is evident. However, it is difficult to quantify the severity of this manufacturing defect from these X-ray micro-CT virtual slices with confidence due to high density of fibre packing (the distance between fibres is below the voxel size) and low contrast between fibre and matrix. Initial fibre misalignment angle is used to describe the severity of fibre misalignment, which can be measured by optical microscopy examination using the 
Yurgartis [32] technique. The overall range of initial fibre angle measured is from $-1.85^{\circ}$ to $1.65^{\circ}$ with $95 \%$ of fibres lying within $\pm 1.5^{\circ}$ of the fibre axis, as shown in Fig. 3 b. The distribution of fibre misalignment is narrower in specimens made using the SSRI method than the typical values in UD CFRP laminates [33] and rods [34], suggesting they will be less prone to promote fibre buckling/kinking. The slightly unsymmetrical distribution might be attributed to gravity in the manufacturing process. As the glass tube full of fibres lay horizontally, during the resin infusion process the resin flow front was not uniform (see Fig. 1). Thus the fibres have a slight tendency to misalign favourably in one direction with the flowing resin.

The X-ray micro-CT virtual cross-sections (Fig. 3) show the presence of an elongated void along the fibre direction and localised micro-voids; these probably arise because that it is difficult for air bubbles to be expelled through the closely packed fibres without the aid of flow media. After being cured, the air bubbles remaining in the composite become voids, observed as relatively dark regions in Fig. 3. Micro-voids have been observed both beside and at the tip of such elongated voids. The micro-voids are discontinuously located between the fibres, being separated by resin ligaments. It can also be observed that fibres are more severely misaligned near the voids than at other regions. Generally, the void content is below $1 \%$ calculated from segmented void volume in X-ray micro-CT datasets.

\subsection{Compressive failure of UD CFRP rods}

The failure of waisted cylindrical carbon fibre-epoxy composite rod specimens generally occurred catastrophically at stress of $910 \pm 60 \mathrm{MPa}$ with no damage visible prior to failure. For samples that fractured into two halves, the fracture surface was generally inclined at $10-20^{\circ}$ to the horizontal plane and located close to the machined transient region, where the cut fibres can lead to local stress concentration, triggering longitudinal splitting and fibre bending. 
Some fibre brooming is evident in the bottom half of the specimen (sample A), see Fig. 2b.

Fig. 2c shows a typical sample (sample B) scanned by X-ray micro-CT, which did not fail into two parts.

\subsection{Macro kink-band geometry}

In order to observe damage at the fibre scale, fracture surfaces were examined under SEM (see Fig. 4). The results indicate that kink band formation is the dominant failure mechanism, and the geometrical parameters of the kink bands are similar across different samples. Generally multiple kink bands were observed, as shown in Fig. 4b. The narrow bands are 25$60 \mu \mathrm{m}$ wide, while the wider band is $80-90 \mu \mathrm{m}$ wide. Fibres in the adjacent two narrow bands were aligned along the same direction. However, the fibre rotation angle and kink-band boundary angle could not be measured directly from these SEM images, as the view was inclined with respect to the kink plane.

Moreover, damage below the fracture surface cannot be revealed by SEM. By contrast, X-ray micro-CT enables the 3D morphology of the kinking damage zone after failure to be determined and analysed for the partially failed intact sample B (Fig. 5). External examination of the sample reveals evidence of shear failure towards the end of the gauge section possibly due to local stress concentration induced by machining and probably reduced local stiffness due to discontinuous fibres. Fig. 5b exhibits a typical virtual XZ cross-section of the kinked region taken from the X-ray tomogram. Great care was taken to ensure the sample was oriented so as to view the kink band sideways on. To enable this the XY coordinate directions for the X-ray tomogram were selected such that the primary shear causing the kink bands lies within the $\mathrm{XZ}$ plane. Thus the geometric parameters can be measured directly from $\mathrm{XZ}$ virtual sections. Unlike the angled view in the SEM images, the measurements were made on the virtual longitudinal sections from the tomogram such as that 
in Fig. 5b. These provide more insight because they average the values in multiple virtual XZ cross-sections along the $\mathrm{Y}$ direction.

The geometric parameters of the kink bands are: $\omega \approx 20-320 \mu \mathrm{m}, \beta \approx 11-40^{\circ}$ and $\Phi\left(\varphi+\varphi_{o}\right) \approx$ $18-52^{\circ}$ in sample B. The damage zone has almost completely propagated through the whole sample with undamaged regions around the periphery holding the sample together. As many as six individual narrow kink bands can be seen on the inclined left-hand side of the sample, as shown in Fig. 5b. The fibres in the central four bands are aligned at approximately the same angle, while small angular change in fibre direction was observed in the top and bottom narrow bands, in accordance with the observations of Vogler and Kyriakides [13].

Fig. 6 shows the XY, XZ and YZ virtual cross-sections of the sample across the damage zone. The boundaries of the wide kink band in Fig. 6c were clearly defined by fibre breakage, indicating full development of the kink band. While in Fig. $6 \mathrm{~b}$ and $\mathrm{d}$ some of the fibres at the boundary of the wide kink band had buckled but not fractured. The discontinuous boundaries at the outer layer of the rod indicate that in these regions, the material is at an earlier stage relative to that in the centre of the sample. The geometry of each fully developed kink band was found to be consistent through the specimen along the $\mathrm{Y}$ axis. In the compressive failure of high aspect ratio laminates, out-of-plane kink bands are dominant due to the lack of constraint in the through-thickness direction [12]. The specimen tested in the current study is cylindrical, so that the lateral constraint is similar in all directions. Nevertheless the kink bands formed predominantly within the same plane across the sample (defined as the $\mathrm{XZ}$ plane) except for a few isolated regions. The $\mathrm{YZ}$ cross-sections along $\mathrm{X}$ axis show that the boundary planes of the wide kink band are parallel and perpendicular to the loading axis, as can be seen in Fig. 6e. 


\subsection{Three-dimensional damage morphology}

All the fully developed kink-band boundaries and three representative longitudinal splits along the fibre direction were segmented and visualised (see Fig. 7), to better understand the 3D damage morphology in the kinking region.

Fully developed kink-band boundaries were defined by fibre breaks. For the wide band, the fibre angle changed abruptly at the boundary, while for the narrow bands, additional fibre rotation was not observed. From the side view in Fig. 7a, all the band-boundary planes were found to be inclined at $\sim 25^{\circ}$ to the $\mathrm{X}$ direction, with slight variation and bending in $3 \mathrm{D}$ due to local microstructure and stress state. The middle crack planes formed by fibre breaks were developed with the formation of multiple narrower kink bands and the width of each kink band ranges between $25 \mu \mathrm{m}$ and $100 \mu \mathrm{m}$. As depicted in Fig. 7b, the kink-band boundary planes were shaped differently. The upper and lower boundaries, delineating the wide band, have almost propagated across the entire specimen; while the middle planes, representing the boundaries of narrower bands, are sickle-shaped localised at one side of the circumference. The difference in the planar shape might indicate different triggering and propagating mechanisms of damage.

The longitudinal splitting parallel to the fibre direction in the 2D cross-sections formed 3D curved planes in the kinked volume, as shown in Fig. 7c. The morphology of these planes changes with position along the $\mathrm{X}$ direction. Three typical longitudinal splits were segmented near two maximum-bending surfaces and at the centre of the specimen, as shown in Fig. 7a.

Fig. 7c demonstrates that longitudinal splits I and III were curved as the circumference of the specimen; while the waviness of longitudinal split II was because the fibre rotation angle varied through the sample through the Y direction. The morphology of the longitudinal splitting planes suggests that its propagating direction is roughly along the $\mathrm{Y}$ axis. It can be seen in Fig. 7a that the formation of longitudinal split I has stopped the propagation of fibre 
breakage at the lower kink-band boundary by releasing the stored strain energy. It is also found that longitudinal split III corresponds to the indentation highlighted in Fig. 7b. It is likely that the upper boundary originates from the split, as has been observed by Hapke et al. [11].

\subsection{Micro damage mechanisms}

Fig. 8a shows a SEM image at a higher-magnification in which micro-cracks in the matrix, longitudinal splitting between fibres and fibre breakage can be observed. Most of the kinked fibres fractured into two parts either perpendicular or angled to the fibre axis. Feature 5 in Fig. 8a displays fibre failure into three sections with the formation of a wedge, which is assumed to be a post-failure pattern from bifurcation of shear fractures [35]. Meanwhile, it is noted that the failure surfaces of individual fibres can be divided into two zones, which are associated with tensile and compressive failure of the fibre, as shown in Fig. 8b, indicating fibre bending failure originated from instability. Along with the bending of fibres, extensive debonding between fibre and matrix occurs at the maximum bending points, as shown in Fig. $6 \mathrm{~b}$ and Fig. $8 \mathrm{c}$.

In 3D X-ray micro-CT data, by carefully analysing sequential XZ cross-sections through the sample, the geometric correlation between different damage mechanisms can be identified. Fig. 9 shows close-up views of small region-of-interest in three adjacent XZ planes along the Y axis. The matrix micro-cracks appeared to be localised between a longitudinal split and fibre breakage. The morphology of the micro-cracks is similar to that reported by Gutkin et al. [36]. They proposed that the micro-cracks would eventually coalesce into a longitudinal split, which can be validated by the observation here that the longitudinal split and the microcracks are connected in sequential images. The fibre fracture plane was inclined at $\sim 45^{\circ}$ to the fibre axis, indicating the presence of shear stress. 


\subsection{Formation of kink bands}

By observing fibres at various locations in the kinking volume, we can potentially track the status of fibres before failure. As seen in Fig. 6, some of the fibres at the boundary of the wide kink band are heavily buckled but did not fracture. The discontinuous boundaries with both broken and unbroken fibres indicate that curvature of unbroken fibres should be close to the maximum bending curvature that the fibres can undergo prior to fracture. The smallest radius of curvature of the unbroken fibres corresponding to extent of bending at fracture was measured using ImageJ to be $\sim 280 \mu \mathrm{m}$ (40 fibre diameters). Weaver and Williams [29] observed larger radius of curvature ( $\sim 530 \mu \mathrm{m}, 78$ fibre diameters) of unbroken fibres in Modmur Type II carbon fibre/epoxy composite rods failed under axial compression with hydrostatic pressure. According to Weaver and Williams, if it is assumed that each fibre was strained in tension and compression equally in reference to its neutral axis $\left(\varepsilon_{\mathrm{T}}=\varepsilon_{\mathrm{c}}\right)$, the maximum elastic strain at the surface would be $\varepsilon_{\mathrm{T}}=\varepsilon_{\mathrm{c}}=$ (fibre diameter) $/(2 \times$ radius of curvature $)=1.25 \%$, which is below the tensile failure strain $2.1 \%$ of the T700 carbon fibres as specified in the manufacturer's data sheet. As our values were measured in unloaded specimens, elastic recovery (spring back) will have taken place following unloading the compressive load. Therefore, even larger curvature (higher strains) would have been sustained in the fibre during buckling.

Although only post mortem X-ray micro-CT analysis was conducted, a comprehensive picture of the damage could be gained from X-ray micro-CT virtual cross-sections at different positions along the damage propagating direction. This provides some clues as to the materials' behaviour at different stages during the loading process. Hapke et al. [11] suggested that only the initial band is ever found to propagate through the whole width of the specimen, and secondary bands terminate when the shared boundary with the initial bands 
stop. In terms of this finding, it is appropriate to consider the top and bottom boundaries as the primary fibre kink fracture planes. As shown in Fig. 7a at the upper concave side, longitudinal split III occurs due to transverse tensile stress induced by axial compressive load, and then reduces the lateral support of the fibres, which bend and break to form the top boundary. At the lower convex side, fibre rotation has exceeded the maximum bending angle the fibre can bear so that fibres break and the bottom boundary is developed. In other words, longitudinal splitting reduces fibre lateral support and promotes fibre micro-buckling, which is a fibre instability damage mode that leads to kink-band formation as the applied load increases. In these processes, shear stress across the damage zone, as evidenced by fibre shear breaks, also contributes to fibre fracture. Nevertheless, it is not possible to determine from the post-failure image, the real sequence of events (e.g. fibre micro-buckling, fibre/matrix debonding and fibre fracture) in kink-band formation and the evolution of multiple kink bands in this experiment, which requires further verification with in situ observation.

\section{Conclusions}

Both 2D and 3D observations demonstrate that the formation of kink bands is the dominant failure mode in all the UD CFRP samples tested under axial compression. Moreover, the development of the SSRI manufacturing method proves to be effective in improving the quality of small-diameter UD cylindrical composite rods, which is essential for future timelapse studies. The damage morphology has been visualised in 3D by segmenting the postfailure X-ray micro-CT data, focusing on the boundaries of the kink-band and longitudinal splitting along the fibre direction. 2D cross-section images lying in the kink-band plane also serve to the better understanding of the failure pattern. The main findings regarding the postfailure kink bands include: 
- Kink-band boundaries are essentially planar (2D) being inclined at $\sim 25^{\circ}$ to the horizontal axis with slight local variation and bending in 3D. This angle is similar to observations in other CFRP systems, which ranges from $15^{\circ}$ to $30^{\circ}$;

- Longitudinal splitting along the fibre direction form curved planes in 3D, accommodating misfit resulted from fibre buckling/kinking;

- Matrix micro-cracks are geometrically connected with longitudinal splitting and fibre breaks in $3 \mathrm{D}$;

- The maximum curvature of unbroken fibres observed at partially developed kink-band boundaries is with a radius of curvature of $\sim 280 \mu \mathrm{m}$ (40 fibre diameters). Fibre breaks under combined bending and shear stress, forming kink-band boundaries.

The study enables a new level of understanding of kink-band morphology and damage mechanisms in 3D, which can be employed to optimise analytical and numerical models of kink bands. The high-speed and cooperative nature of kink-band formation has been noticed. This catastrophic nature of failure is challenging to real-time monitoring of damage evolution under mechanical loading (time-lapse study).

\section{Acknowledgements}

We thankfully acknowledge EPSRC for funding the Henry Moseley X-ray Imaging Facility through grants (EP/F007906/1, EP/F001452/1 and EP/M010619/1). We would like to thank the support from Northwest Composites Centre for composite processing. The first author is grateful to China Scholarship Council for funding a $\mathrm{PhD}$ stipend and the University of Manchester for covering the $\mathrm{PhD}$ fees. The first author would also like to thank Professor Silvestre Pinho for discussions and suggestions at her $\mathrm{PhD}$ viva. 


\section{References}

[1] Ahn J, Waas AM. Finite element model for compressive failure of notched uniply composite laminates under remote biaxial loads. ASME J Eng Mater Technol $1999 ; 121: 1-7$.

[2] Berbinau P, Soutis C, Guz IA. Compressive failure of $0^{\circ}$ unidirectional carbon-fibrereinforced plastic (CFRP) laminates by fibre microbuckling. Compos Sci Technol 1999;59:1451-5.

[3] Budiansky B, Fleck NA. Compressive failure of fibre composites. J Mech Phys Solids $1993 ; 41: 183-211$.

[4] Soutis C. Fibre reinforced composites in aircraft construction. Prog Aerosp Sci 2005;41:143-51.

[5] Dow NF, Gruntfest IJ. Determination of most needed potentially possible improvements in materials for ballistic and space vehicles. TJS R 60 SD, General Electric Co, Space Science Laboratory; 1960, p. 389.

[6] Fleck NA. Compresssive failure of fiber composites. Adv Appl Mech 1997;33:43-119.

[7] Chaplin CR. Compressive fracture in undirectional glass-reinforced plastics. J Mater Sci 1977; 12:347-52.

[8] Hahn HT, Sohi M, Moon S. Compression failure mechanisms of composite structures. NASA Contractor Report 3988; 1986.

[9] Pimenta S, Gutkin R, Pinho ST, Robinson P. A micromechanical model for kink-band formation: Part I—Experimental study and numerical modelling. Compos Sci Technol 2009;69:948-55.

[10] Vogler TJ, Kyriakides S. On the axial propagation of kink bands in fiber composites : Part i experiments. Int J Solids Struct 1999;36:557-74.

[11] Hapke J, Gehrig F, Huber N, Schulte K, Lilleodden ET. Compressive failure of UD- 
CFRP containing void defects: In situ SEM microanalysis. Compos Sci Technol 2011;71:1242-9.

[12] Sutcliffe MPF, Fleck NA. Microbuckle propagation in carbon fibre - epoxy composites. Acta Metall Mater 1994;42:2219-31.

[13] Vogler TJ, Kyriakides S. Initiation and axial propagation of kink bands in fiber composites. Acta Mater 1997;45:2443-54.

[14] Pimenta S. Micromechanics of kink-band formation. Master thesis, Imperial College London, 2008.

[15] Sivashanker S, Fleck NA, Sutcliffe MPF. Microbuckle propagation in a unidirectional carbon fibre-epoxy matrix composite. Acta Mater 1996;44:2581-90.

[16] Maire E, Withers PJ. Quantitative X-ray tomography. Int Mater Rev 2014;59:1-43.

[17] Elliott JC, Dover SD. X-ray microtomography. J Microsc 1982;126:211-3.

[18] Moffat AJ, Wright P, Buffière J-Y, Sinclair I, Spearing SM. Micromechanisms of damage in 0 splits in a [90/0] s composite material using synchrotron radiation computed tomography. Scr Mater 2008;59:1043-6.

[19] Yu B, Bradley RS, Soutis C, Hogg PJ, Withers PJ. 2D and 3D imaging of fatigue failure mechanisms of 3D woven composites. Compos Part A Appl Sci Manuf $2015 ; 77: 37-49$.

[20] Lambert J, Chambers AR, Sinclair I, Spearing SM. 3D damage characterisation and the role of voids in the fatigue of wind turbine blade materials. Compos Sci Technol $2012 ; 72: 337-43$.

[21] Nikishkov Y, Airoldi L, Makeev A. Measurement of voids in composites by X-ray Computed Tomography. Compos Sci Technol 2013;89:89-97.

[22] Aroush DR-B, Maire E, Gauthier C, Youssef S, Cloetens P, Wagner HD. A study of fracture of unidirectional composites using in situ high-resolution synchrotron X-ray 
microtomography. Compos Sci Technol 2006;66:1348-53.

[23] Bull DJ, Helfen L, Sinclair I, Spearing SM, Baumbach T. A comparison of multi-scale 3D X-ray tomographic inspection techniques for assessing carbon fibre composite impact damage. Compos Sci Technol 2013;75:55-61.

[24] Sket F, Enfedaque A, Alton C, González C, Molina-Aldareguia JM, Llorca J. Automatic quantification of matrix cracking and fiber rotation by X-ray computed tomography in shear-deformed carbon fiber-reinforced laminates. Compos Sci Technol 2014;90:129-38.

[25] Ueda M, Mimura K, Jeong T-K. In situ observation of kink-band formation in a unidirectional carbon fiber reinforced plastic by X-ray computed tomography imaging. Adv Compos Mater 2014:1-13.

[26] Wang Y, Soutis C, Withers PJ. X-ray microtomographic imaging of kink bands in carbon fibre-epoxy composites. 16th European Conference on Composite Materials, Seville, Spain, 20-26 June 2014.

[27] Titarenko S, Titarenko V, Kyrieleis A, Withers PJ, De Carlo F. Suppression of ring artefacts when tomographing anisotropically attenuating samples. J Synchrotron Radiat 2011;18:427-35.

[28] Hodgkinson JM. Mechanical testing of advanced fibre composites. Elsevier; 2000.

[29] Weaver CW, Williams JG. Deformation of a carbon-epoxy composite under hydrostatic pressure. J Mater Sci 1975;10:1323-33.

[30] Couque H, Albertini C, Lankford J. Failure mechanisms in a unidirectional fibrereinforced thermoplastic composite under uniaxial, in-plane biaxial and hydrostatically confined compression. J Mater Sci Lett 1993;12:1953-7.

[31] Feldkamp LA, Davis LC, Kress JW. Practical cone-beam algorithm. J Opt Soc Am A $1984 ; 1: 612-9$. 
[32] Yurgartis SW. Measurement of small angle fiber misalignments in continuous fiber composites. Compos Sci Technol 1987;30:279-93.

[33] Jelf PM, Fleck NA. Compression failure mechanisms in unidirectional composites. J Compos Mater 1992;26:2706-26.

[34] Soutis C. Compression testing of pultruded carbon fibre-epoxy cylindrical rods. J Mater Sci 2000;35:3441-6.

[35] Boll DJ, Jensen RM, Cordner L, Bascom WD. Compression behavior of single carbon filaments embedded in an epoxy polymer. J Compos Mater 1990;24:208-19.

[36] Gutkin R, Pinho ST, Robinson P, Curtis PT. On the transition from shear-driven fibre compressive failure to fibre kinking in notched CFRP laminates under longitudinal compression. Compos Sci Technol 2010;70:1223-31. 
Fig. 1. Schematic of the SSRI manufacturing method developed to fabricate UD rods.

Fig. 2. (a) Schematic diagram of the specimen geometry (dimensions in $\mathrm{mm}$ ) showing the carbon fibre/epoxy sample (black) and the aluminium tabs (white). Photographs showing typical failure of the composite samples: (b) Sample A fractured into two parts, and (c) Intact sample B after partial failure showing an inclined damage zone across the sample.

Fig. 3. (a) X-ray micro-CT virtual cross-section along the nominal fibre axis of the composite rod, showing an elongated void and micro-voids, and (b) Initial fibre misalignment angle distribution in carbon fibre/epoxy rods made by the SSRI method.

Fig. 4. (a) Secondary electron SEM image (plan view) of the lower fracture surface of sample A ( 1.5 mm gauge diameter), and (b) magnified secondary electron SEM image (oblique view) showing multiple kink bands of variable width (yellow dashed lines indicate kink-band boundaries).

Fig. 5. (a) 3D X-ray micro-CT volume rendering of the damage zone of sample B oriented so as to view the kink sideways on. (b) A typical X-ray micro-CT virtual XZ cross-section located in the middle of the sample showing kink bands and associated damage mechanisms. Most of the bands lie in the XZ plane, thus $\omega$ (white), $\beta$ (red) and $\Phi$ (yellow) can be measured as indicated.

Fig. 6. X-ray micro-CT virtual cross-sections of sample B: (a) XY, (b), (c) and (d) XZ, and (e) YZ, showing different views of kink bands inside the rod (yellow dashed lines indicate kinkband boundaries). 
Fig. 7. Segmented and extracted 3D volume of damage from X-ray micro-CT data: (a) Side view of planes of fibre breakage (purple) normal to, and three splits (yellow) parallel to, the fibre direction. The upper and lower fibre-fracture planes delineate a wide kink band, within which multiple narrow bands that are similarly inclined lie, (b) Top view of kink-band boundaries defined by fibre breakage, categorised in three groups according to their location and morphology: upper, middle and lower, and (c) Angled views of the three splits at different locations in the specimen, numbered I, II and III.

Fig. 8. (a) SEM image of the fracture surface (sample A) showing matrix failure, splitting and different modes of fibre failure associated with kink-band formation (numbered). (b) Highmagnification SEM image showing the failure pattern of individual fibres. The fracture surface of one fibre consists of a compressive zone and a tensile zone. (c) Schematic diagram showing localised debonding at fibre maximum-bending points.

Fig. 9. Adjacent X-ray micro-CT virtual XZ cross-sections of sample B (two sequential images in between were not shown) showing the transition between split (white), microcracks (yellow) and fibre breakage (red). 
Table 1. X-ray micro-CT scanning parameters.

\begin{tabular}{|l|l|l|}
\hline CT Scan & As-manufactured & Post-failure \\
\hline CT Machine & Zeiss Xradia 520 Versa & Zeiss Xradia 400 Bay \\
\hline Accelerating voltage $(\mathrm{kV})$ & 40 & 40 \\
\hline Source power $(\mathrm{W})$ & 3 & 10 \\
\hline Optical magnification & $4 \mathrm{x}$ & $10 \mathrm{x}$ \\
\hline Source to sample distance $(\mathrm{mm})$ & 10 & 40 \\
\hline Sample to detector distance $(\mathrm{mm})$ & 46 & 12 \\
\hline Exposure time $(\mathrm{s})$ & 40 & 40 \\
\hline Number of Projections & 1001 & 1001 \\
\hline Voxel size $(\mu \mathrm{m})$ & 0.6 & 1.1 \\
\hline
\end{tabular}




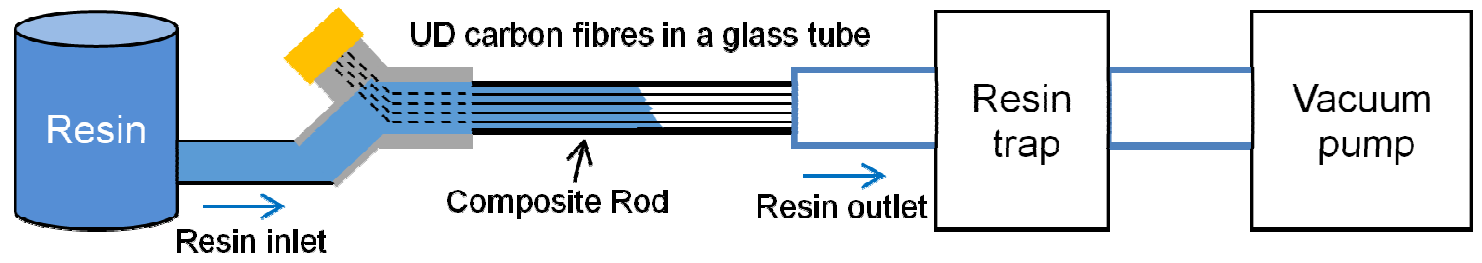



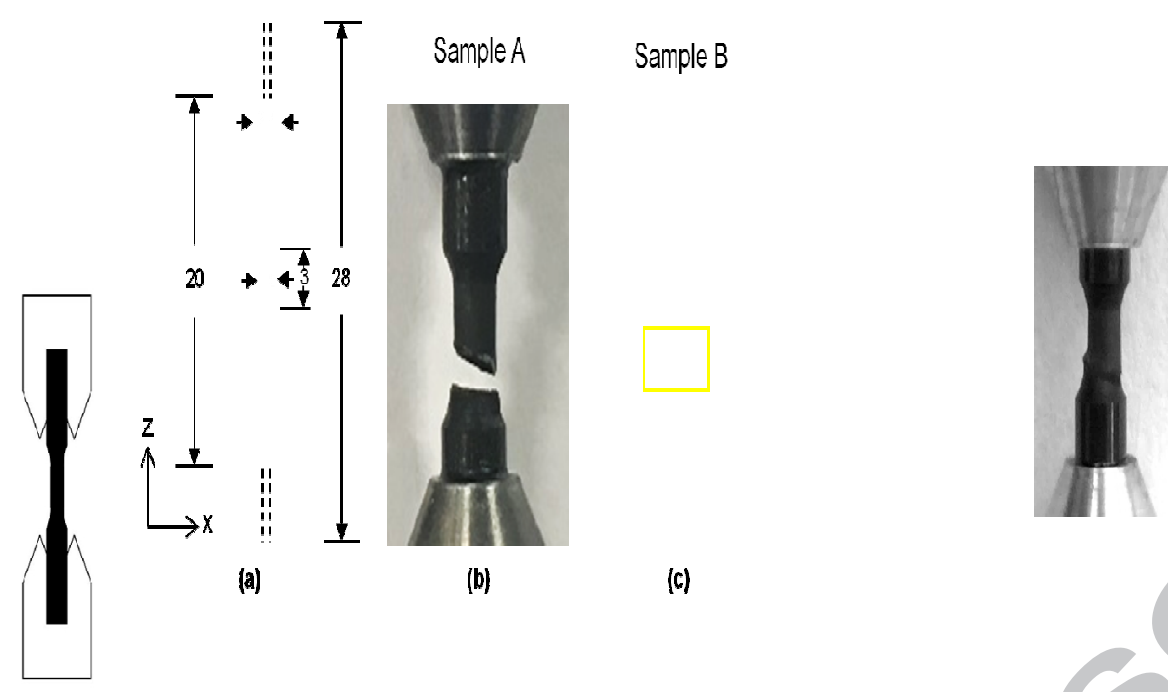

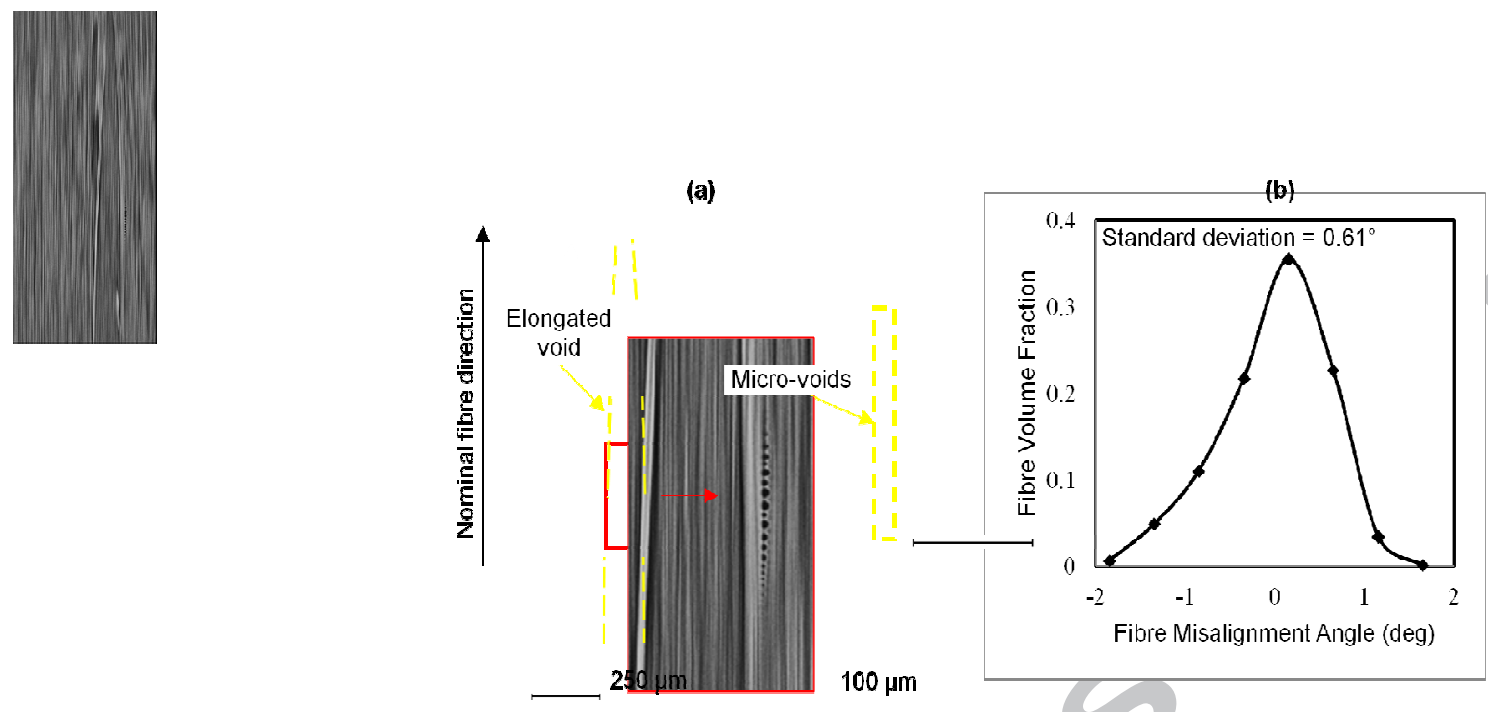

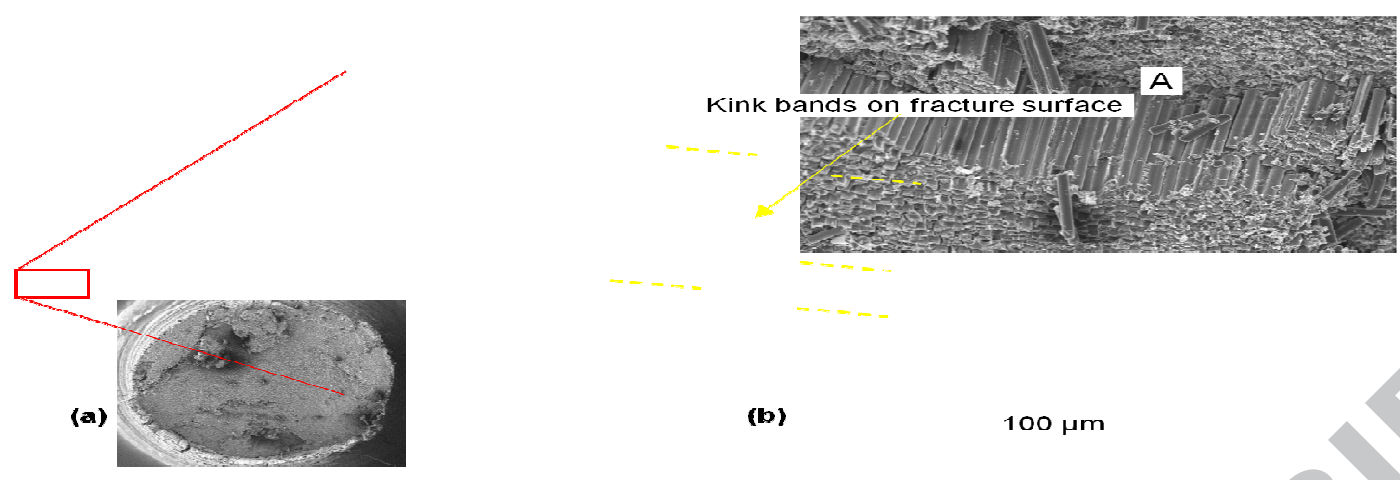

(b)

$100 \mu \mathrm{m}$

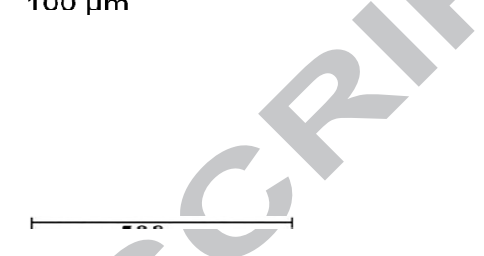




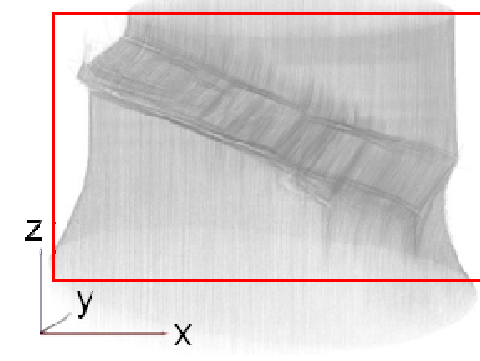

(a)

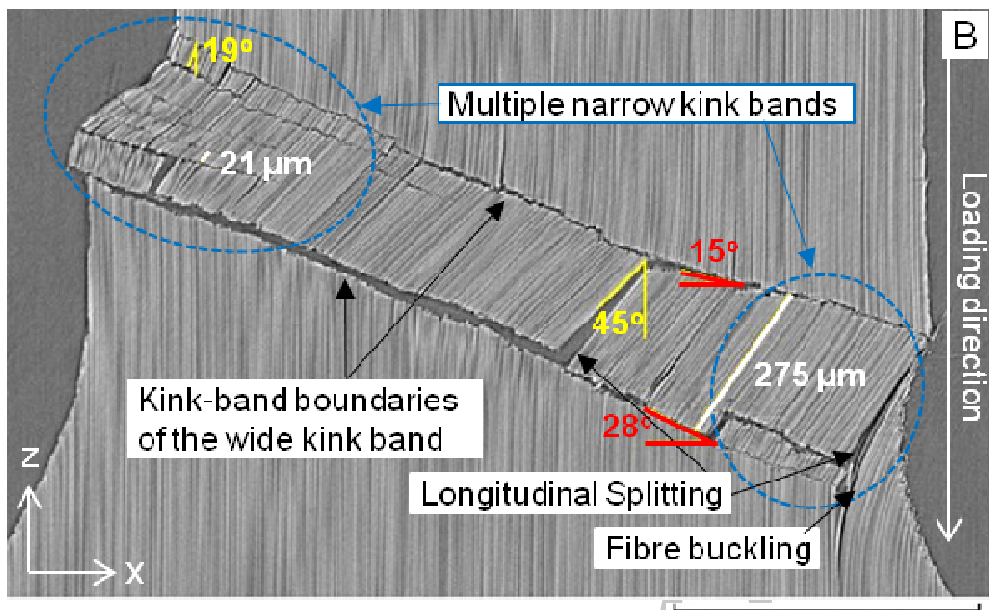

(b)

$500 \mu \mathrm{m}$ 

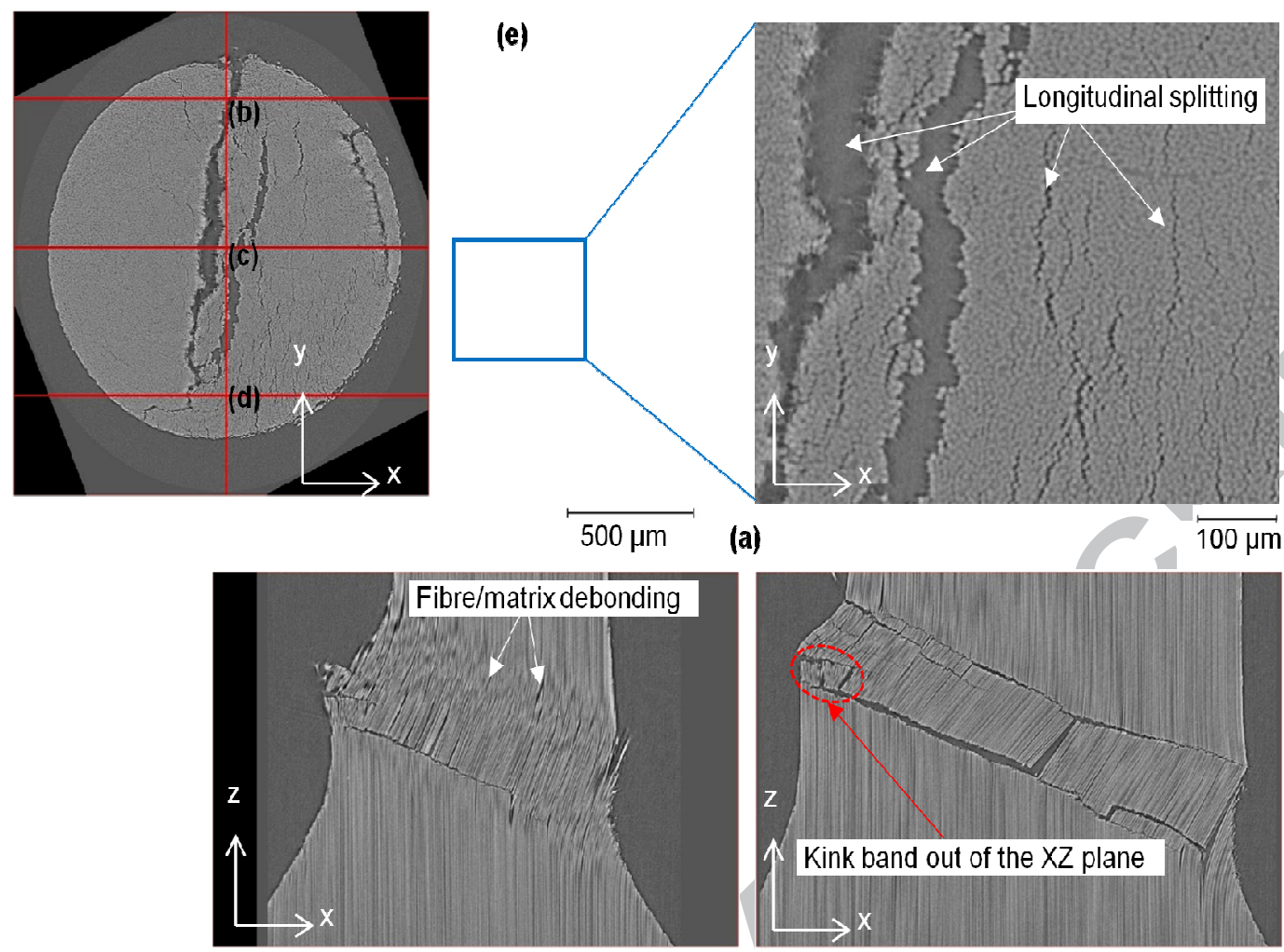

(b)

(c)

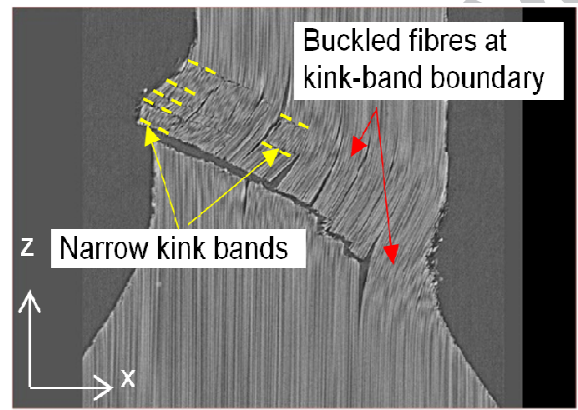

(d)

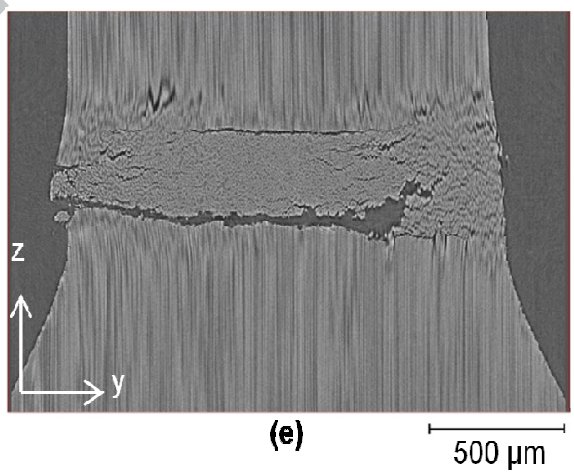




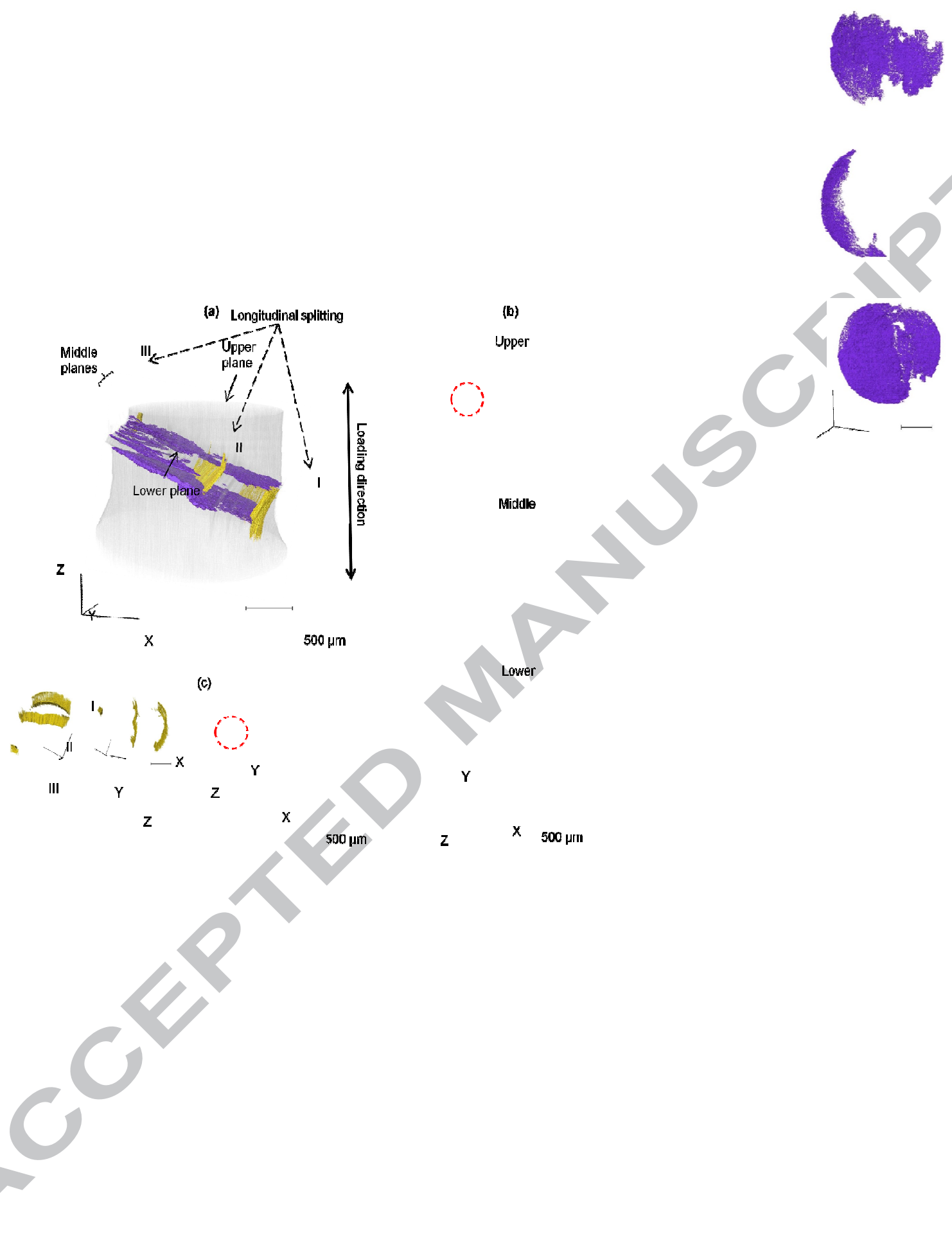




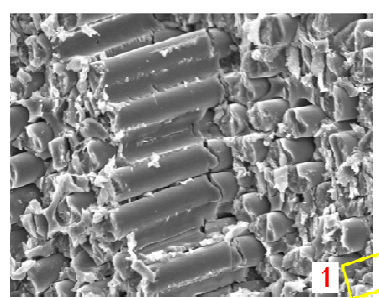

(a)

30

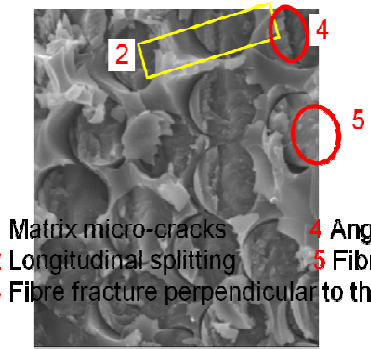

$10 \mu \mathrm{m}$

A

6

Tension (T) $\quad$ C $\quad$ T

Compression (C)

6 Fibre/matrix

7 Fibre micro-buckling with debonding

at two maximum-bending points (c)

7

$\mathrm{T}$

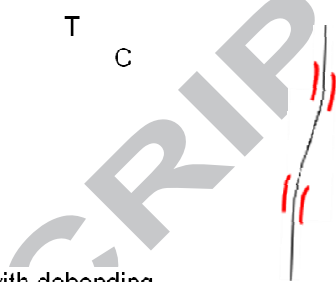

Fibre fracture with a wedge hore direction um-bending points 

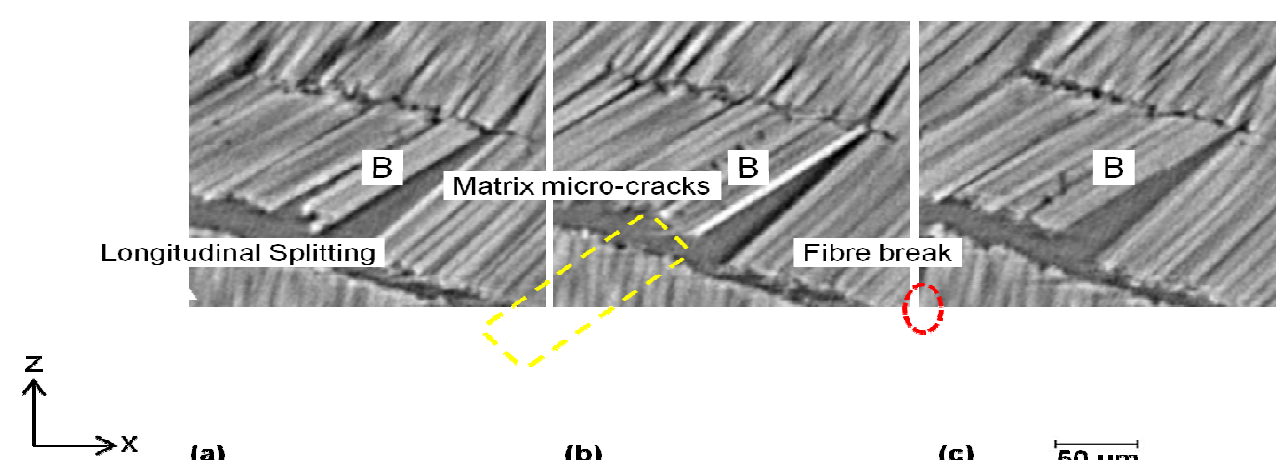

(a)

(b)

(c) 